\title{
Optimization of grape cultivation based on resource-saving elements of agricultural technology
}

\author{
Natalia Urdenko*, Magomedsaigit Beibulatov, Nadezhda Tikhomirova, and Roman Buival \\ Federal State Budget Scientific Institution All-Russian National Research Institute of Viticulture and \\ Winemaking Magarach of the RAS, Kirova Str., 31, 298600 Yalta, Republic of Crimea, Russian \\ Federation
}

\begin{abstract}
The research on the development of resource-saving cultivation technologies of new for Crimea clones of wine grape varieties in comparison with traditional cultivation technologies of example varieties was carried out in order to ensure sustainable economic production of raw materials. As a result of the research, the economic efficiency of cultivation of three clones of wine grape varieties in the conditions of the South Coast zone of Crimea was assessed. The effect of varietal agricultural technology elements, aimed at increasing the yield and its quality parameters, profitability of production of raw materials as well as manual labor optimization was also evaluated. The results showed that spiral cordon AZOS-1 on 'Aleatiko' clone 802 with 18 eyes load and 'Muscat Blanc' clone VCR-3 with 26 eyes load and short pruning of fruit canes; unilateral horizontal cordon on 'Muscat Blanc' clone VCR-3 with load of 33 eyes and long pruning of fruit canes; bilateral horizontal cordon on the variety 'Cabernet-Sauvignon' clone R-5 with 36 eyes load and short and medium length of grape canes provide high values of embryonic productivity, shoot-forming capacity, high yield and base wines of high quality. The efficiency of developed elements of the technology of clones of wine grape varieties ranged from 95.5 to $181.7 \%$. Using of AZOS-1 training and short pruning allows to reduce the cost of bush management, the effective time is 1.44 less.
\end{abstract}

\section{Introduction}

Grapevine cultivar is one of the most important technologically and economically efficient crops in agricultural production in the Southern Federal District of the Russian Federation and Crimea. The value of grapes and its products for humans is great. Consistent productivity of vineyards is ensured by selection of a rational assortment of plantations and development of grape cultivation technologies.

One of conditions and strong requirements, stabilizing the state of the industry is the introduction of effective economic management manners based on principles of local

\footnotetext{
* Corresponding author: natasha.urdenko@mail.ru
} 
intensification of the existing resource potential of economic entities cultivating grapes [1, 2].

Crimea is characterized by unique distinctive features for development of viticulture and winemaking due to its special geopolitical position, existing system of internal and external economic relations and production capacities, investment opportunities and social conditions, accumulating centuries of experience in the production of grapes and products of its processing.

The research priorities of scientific and technological development of the Russian Federation are the areas that will follow to scientific and technical results in order to work out the technologies for innovative development of the domestic market, product quality improving and steady position of Russia in the international market. Such directions will ensure the transition to high-productive agricultural economy and will contribute to the increase in import substitution in Russia [3], which is a governmental solution of the issues of commercial and food security. The competitiveness of products of viticulture and winemaking supplied abroad and technological development of Russian economy depend on implementation of the projects.

Main tasks in the development of viticulture of the Republic are to increase the cropping capacity of vineyards and the efficiency of viticulture, as well as to introduce new promising varieties and technologies [4]. To solve such complex problems, it is necessary for the technology of commercial cultivation of grapes to be based on a scientifically grounded system of intensive cultivation, geared towards biological peculiarities of grape varieties and clones, natural, technical and economic conditions in order to obtain high and stable yields of the required quality. The technology should be improved and distinguished depending on the varietal composition of plantations, products used, microclimatic and soil conditions. [5].

Modern selection of low-cost technologies is needed to reduce the financial costs for obtaining the unit of output $[6,7,8]$.

Improving of labor efficiency in viticulture is the most important condition of intensive development of production. Taking into account the dramatic reduction in the labor intensity of work in the vineyards and a necessity of simultaneous increase in the cropping capacity and quality, this problem can be solved by using training forms that reduce the cost of bush management [9-14].

In this connection, the cultivation of grape varieties using the forms of training with high potential productivity and specific technology, requiring minimal coasts for bush management is very important for producers.

The aim of the research is to develop effective technologies for cultivation of grapes to ensure sustainable production; the assessment of their economic efficiency to recommend for production.

\section{Materials and Methods}

Experimental studies during 2019-2020 were carried out on the basis of Livadiya and Tavrida branches of FSUE PJSC Massandra; laboratory tests -on the basis of Laboratory of agricultural technologies of grapes and biochemistry of wine in FSBSI Magarach of the RAS (Republic of Crimea, Russian Federation).

The studies were carried out according to the generally accepted in viticulture methods and GOSTs (national state standards):

- test for fruit-bearing capacity of eyes - by the method of microscopic examination according to the methodology of Dikan A.P., 2002 (Method for determining the qualitative heterogeneous fruit-bearing capacity of central buds of grape eyes); 
- test for geometric model of a crown and architecture of a grape bush (Methodology of Amirdzhanov A.G., 1982);

- assessment of phytosanitary condition of grape bushes according to methodological guidelines (Test for the degree of development of pests and diseases on commercial grape plantations, 1991) [15];

- assessment of qualitative and physicochemical indicators of grapes: mass concentration of sugars and titratable acids, $\mathrm{pH}$, mass concentration of phenolic substances in must (FS), mass concentration of organic acids according to STO 01580301.001-2016 $[16,17]$ and GOST 32051 [18];

- analysis of table dry base wines according to the following physicochemical indicators: volume fraction of ethyl alcohol, mass concentration of titratable and volatile acids, $\mathrm{pH}$, mass concentration of phenolic substances, mass concentration of organic acids and glycerin according to STO 01580301.002-2016 [19, 20];

- time-study of the working hours spent on pruning grape bushes depending on the specified form, load and length of cane pruning (methods of chronography and snap reading of working hours);

- calculation of the economic efficiency of grape production (Methodology of Chernyavsky A.F.) [21];

- mathematical data processing (Methodology of Dospekhov B.A.) [22].

The type of research is microplot field experiment on production land. Experimental scheme is presented in the table. Each variant is represented by 45 bushes. There are two variants by the length of cane pruning (short - 3-6 eyes and medium - 6-8 eyes). The number of bushes in one replication is 15 pcs.

Bushes of studied introduced varieties 'Aleatiko' 802, 'Muscat Blanc' VCR-3 were shaped according to unilateral cordon AZOS-1 form; planting system was 3.0x1.25 (planted in 2010). Bushes of 'Cabernet-Sauvignon' clone R-5 - bilateral cordon on a medium trunk, planting system $3 \times 1.5$ (planted in 2010); bushes of example varieties unilateral cordon on a medium trunk.

Table 1. Scheme of development the cultivation technology of new varieties and clones in comparison with the example grape varieties.

\begin{tabular}{|c|c|c|c|c|c|}
\hline Grape variety & $\begin{array}{l}\text { Experiment } \\
\text { variant }\end{array}$ & $\begin{array}{l}\text { Form of bush } \\
\text { training }\end{array}$ & $\begin{array}{l}\text { Load per } \\
\text { bush, } \\
\text { eyes }\end{array}$ & $\begin{array}{l}\text { Length of } \\
\text { fruit cane } \\
\text { pruning, eyes }\end{array}$ & $\begin{array}{l}\text { Number of } \\
\text { fruit } \\
\text { sections, } \\
\text { pcs. }\end{array}$ \\
\hline $\begin{array}{l}\text { 'Aleatiko' clone } \\
802\end{array}$ & Experiment & $\begin{array}{l}\text { Spiral cordon } \\
\text { (AZOS-1) }\end{array}$ & 18 & 3 & 6 \\
\hline $\begin{array}{l}\text { 'Aleatiko' } \\
\text { (example variety) }\end{array}$ & Control & $\begin{array}{l}\text { Unilateral } \\
\text { cordon }(\mathrm{U} / \mathrm{C})\end{array}$ & 36 & 6 & 4 \\
\hline \multirow{2}{*}{$\begin{array}{l}\text { 'Muscat Blanc' } \\
\text { clone VCR-3 }\end{array}$} & $\begin{array}{l}\text { Experiment } \\
\text { I }\end{array}$ & $\begin{array}{l}\text { Unilateral } \\
\text { cordon }(\mathrm{U} / \mathrm{C})\end{array}$ & 33 & 8 & 3 \\
\hline & $\begin{array}{l}\text { Experiment } \\
\text { II }\end{array}$ & $\begin{array}{l}\text { Spiral cordon } \\
\text { (AZOS-1) }\end{array}$ & 26 & 3 & $\begin{array}{l}6+ \\
\text { «lock» }\end{array}$ \\
\hline $\begin{array}{l}\text { 'Muscat Blanc' } \\
\text { (example } \\
\text { variety) }\end{array}$ & Control & $\begin{array}{l}\text { Unilateral } \\
\text { cordon }(\mathrm{U} / \mathrm{C})\end{array}$ & 44 & 8 & 4 \\
\hline \multirow{2}{*}{$\begin{array}{l}\text { 'Cabernet- } \\
\text { Sauvignon' clone } \\
\text { R-5 }\end{array}$} & $\begin{array}{l}\text { Experiment } \\
\text { I }\end{array}$ & \multirow{3}{*}{$\begin{array}{l}\text { Bilateral cordon } \\
(\mathrm{B} / \mathrm{C})\end{array}$} & 36 & 6 & 4 \\
\hline & $\begin{array}{l}\text { Experiment } \\
\text { II }\end{array}$ & & 36 & 3 & 6 \\
\hline $\begin{array}{l}\text { 'Cabernet- } \\
\text { Sauvignon' } \\
\text { (example variety) }\end{array}$ & Control & & 54 & 6 & 6 \\
\hline
\end{tabular}


Vineyards with the varieties under study where the elements of varietal agricultural technology in the South Coast zone of Crimea (SCC) were developing, experienced a lack of moistness and low atmospheric air humidity during the period of prefoliation set in eyes and in the phase of ripening for harvest, which affected the size and quality of crops. Phenological phase of bursting eyes lasted for two weeks. Harvesting time increased by one to two weeks, sugar accumulation in juice of berries decreased due to sudden drops in day and night temperatures.

\section{Results and Discussion}

When researching the selection of grapevine cultivars, varietal technologies with a regulated yield and correct pruning length of fruit canes, it is very important to pay attention to the issues of cropping capacity and fruitification of buds. We have made a comparative analysis of fruit-bearing capacity of buds according to the cane length of the studied clones of varieties, depending on the developed elements of agricultural technology with the example varieties (Figures 1-3). So, in the variety 'Aleatiko' clone 802 (Figure 1), when using the AZOS-1 bush training, the average value of fruit-bearing coefficient $\left(\mathrm{C}_{1}\right)$ exceeded $\mathrm{C}_{1}$ values in the control example variety by 0.48 points. The maximum $\mathrm{C}_{1}$ values are in the zone of 7 and 8 eyes: the 'Aleatiko' clone 802 variety has value of 1.9 , and the example variety -1.71 and 1.75 , respectively.

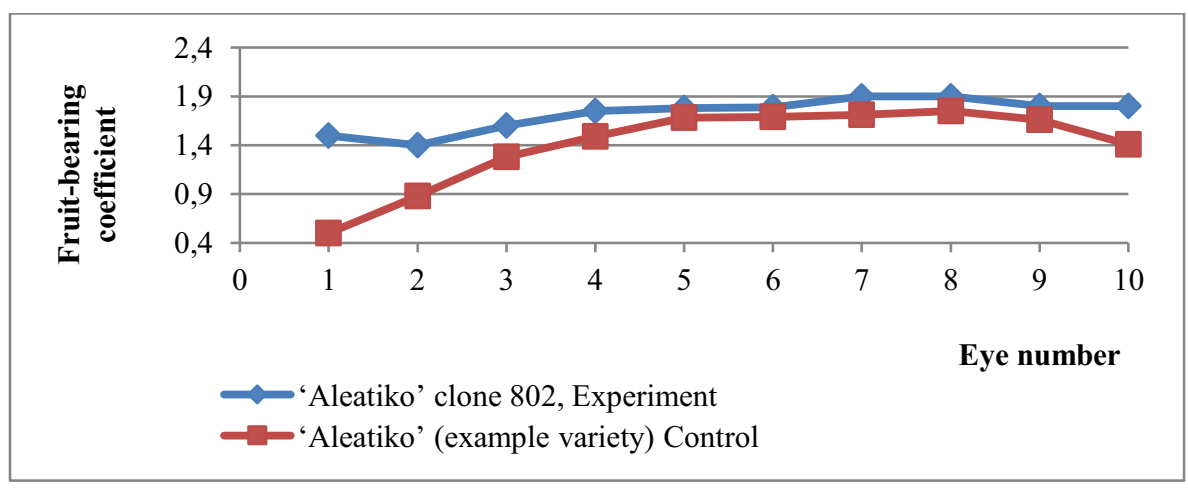

Fig. 1. $C_{1}$ values of eyes along the cane length for 'Aleatiko' clone 802 variety when using elements of varietal agricultural technology under test in comparison with example variety

In the variety 'Cabernet-Sauvignon' clone R-5 (Figure 2), when using AZOS-1 bush training form and medium (experiment I) and short (experiment II) length of pruning, average $C_{1}$ values along the cane length exceeded same values in the control example variety and bush training $\mathrm{B} / \mathrm{C}$ by 0.55 and 0.35 points, respectively. Zone of maximum set of prefoliation for all variants is between 5-7 eyes.

Using of AZOS-1 bush training form on 'Muscat Blanc' clone VCR-3 grape variety (Figure 3), 26 eyes load and 3 eyes short pruning, as well as U/C with 33 eyes load and 8 eyes fruit cane pruning, gives the meaning of $\mathrm{C}_{1}$, exceeding value for the example variety with U/C bush training, 44 eyes load and 8 eyes cane pruning, respectively, by 0.15 and 0.1 points. Zone of maximum set of prefoliation for experiment I and the control is between 6 and 8 eye and for experiment II - from 4 to 8 eye. 


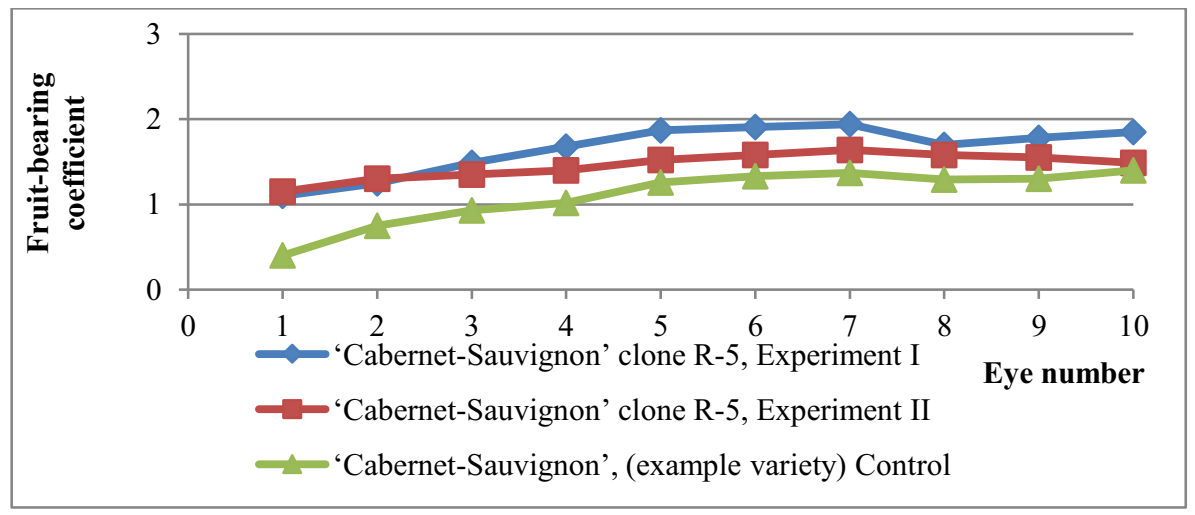

Fig. 2. $\mathrm{C}_{1}$ values for eyes along the cane length for 'Cabernet-Sauvignon' clone R-5 variety when using elements of varietal agricultural technology under test in comparison with example variety

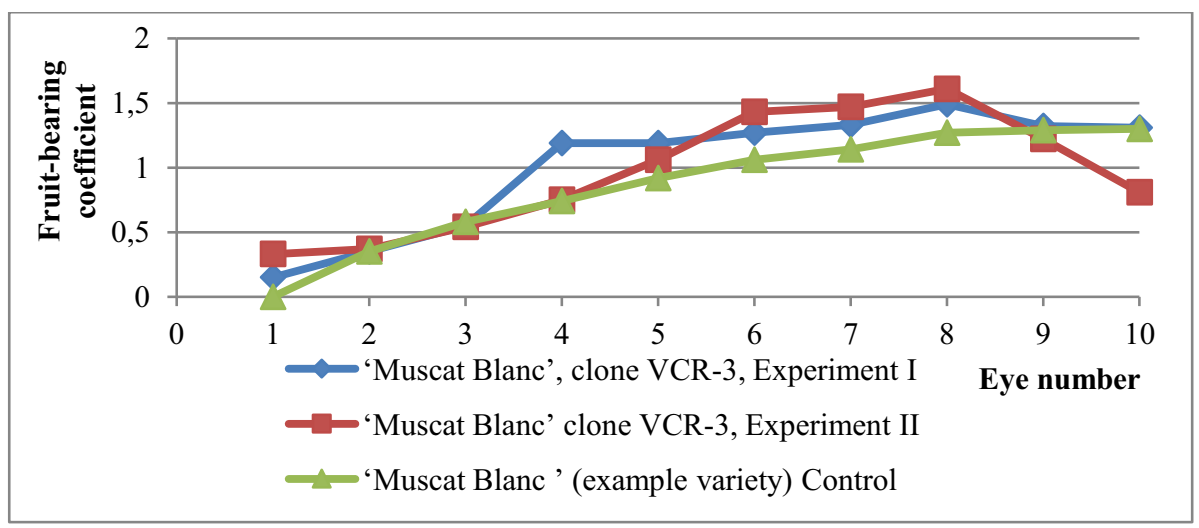

Fig. 3. $C_{1}$ values for eyes along the cane length for 'Muscat Blanc' clone VCR-3 variety when using elements of varietal agricultural technology under test in comparison with example variety

In general, embryonic fruit-bearing of clones of European wine grape varieties in Crimea is directly dependent on the applied elements of varietal agricultural technology and characterized by a good inflorescence initiation over the total cane length, exceeding values of the fruit-bearing coefficient of the example varieties.

Under SCC conditions, the studied clones of varieties with the elements of agricultural technology applied to them were characterized by a high proportion of shoot-forming capacity: in the variety 'Aleatiko' clone 802 these values amounted to $85.0 \%$, which was higher than values of the example variety by $3.8 \%$, respectively.

In 'Muscat Blanc' clone VCR-3 the highest shoot-forming capacity was observed when using the spiral cordon AZOS-1, which was $8.1 \%$ and $3.2 \%$ higher compared to using of $\mathrm{U} / \mathrm{C}$ training and in the example variety (control).

For the variety 'Cabernet-Sauvignon' clone R-5, it is necessary to emphasize a variant with medium pruning length of a fruit cane (experiment I), the rest of values for the variants of the experiment did not differ.

Series of agrotechnical actions influence the yield of a grape plant, providing the filling of trellis space with phytomass, which volume together with density affects the phytoclimate of a bush and development of diseases. Therefore, optimization of crown parameters increases the efficiency of using the energy of solar radiation absorbed by plants and reduces risks of development fungal diseases in a vineyard (Figure 4). 
As a result of the studies, it was found that in the 'Aleatiko' clone 802 variety, during shoots topping and using spiral cordon AZOS-1 form of bush training, the parameters of crown architecture decreased: bush crown volume - by $20 \%$; crown density - by $14 \%$, favorably influencing the phytosanitary condition of a bush. During the growing season, the oidium as one of the most harmful diseases in Crimea, was monitored on the registered bushes. Treatments against diseases and pests of grapes were carried out in accordance with the "Plan of protection economic measures". The percentage of disseminated oidium (leaves) on the topped bushes was 2.4 fold lower in July, and 3 fold lower in August rather than in bushes without topping shoots.

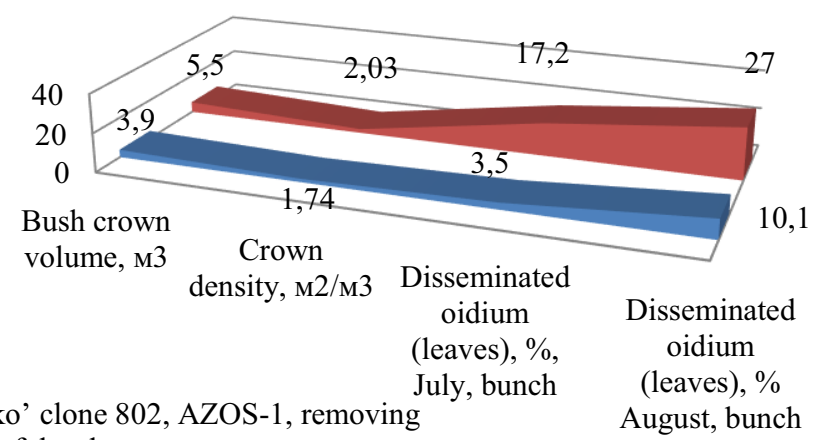

'Aleatiko' clone 802,
the top of the shoots

August, bunch

- 'Aleatiko' clone 802, AZOS-1, without topping shoots

Fig. 4. The effect of varietal agricultural technology elements on parameters of a bush crown and oidium dissemination

An objective technological assessment of grapes should complete all agronomic experiments carried out in the cultivation process of wine varieties, since agrotechnical actions directly impact the quality characteristics of wine. The experiment on the effect of the bush shape on the physicochemical analysis of grapes is presented on example of the 'Aleatiko' clone 802 variety. Grape analysis showed (Table 3) that all samples corresponded to the stage of industrial ripeness and the requirements for grapes intended for industrial processing. The 'Aleatiko' grapes in the AZOS-1 variant showed moderate increase in sugar accumulation (by $1.6 \mathrm{~g} / 100 \mathrm{ml}$ ). At the same time, the $\mathrm{pH}$, mass concentration of titratable acids and the profile of organic acids did not differ significantly between the variants.

Table 3. Physicochemical indicators of grapes and table base wines, depending on bush training.

\begin{tabular}{|l|c|c|c|c|}
\hline \multirow{2}{*}{ Indicator } & \multicolumn{3}{c|}{ Sample's title } \\
\cline { 2 - 5 } & \multicolumn{2}{|c|}{ grape } & \multicolumn{2}{c|}{ base wine } \\
\cline { 2 - 5 } & AZOS-1 & U/C & AZOS-1 & U/C \\
\hline $\begin{array}{l}\text { Mass concentration of: } \\
\text { sugars, g/dm } \text {; g/l }\end{array}$ & 21,8 & 23,4 & 4,1 & 4,0 \\
\hline titratable acids, g/dm / equivalent to tartaric, g/1 & 7,7 & 7,9 & 7,8 & 7,2 \\
\hline $\mathrm{pH}$ & 3,2 & 3,2 & 3,4 & 3,2 \\
\hline Volume fraction of ethyl alcohol, \% & - & - & 10,5 & 10,8 \\
\hline Mass concentration of total dry extract, g/l & - & - & 17,0 & 16,8 \\
\hline $\begin{array}{l}\text { Mass concentration of volatile acids, equivalent to } \\
\text { acetic, g/l }\end{array}$ & - & - & 0,03 & 0,02 \\
\hline Mass concentration of phenolic compounds, mg/1 & - & - & 604 & 514 \\
\hline Mass concentration of glycerin, g/l & - & - & 8,5 & 8,3 \\
\hline
\end{tabular}




\begin{tabular}{|l|c|c|c|c|}
\hline Mass concentration of organic acids, $\mathrm{g} / \mathrm{l}$ & \multicolumn{4}{|l|}{} \\
\hline tartaric & 3,3 & 3,5 & 3,1 & 3,4 \\
\hline malic & 3,6 & 3,4 & 2,6 & 2,4 \\
\hline citric & 0,3 & 0,2 & 0,5 & 0,3 \\
\hline lactic & 0 & 0 & 1,4 & 1,6 \\
\hline amber & 0 & 0 & 0,2 & 0,2 \\
\hline
\end{tabular}

The values of specified parameters, such as content of ethyl alcohol, total dry extract, titratable and volatile acids, corresponded to the requirements of GOST 32030. The values of additional indicators characterizing quality of base wines $(\mathrm{pH}$, mass concentration of glycerin and organic acids) correspond to the ranges typical for genuine table wines.

In the base wine prepared from 'Aleatiko' grape variety in the AZOS-1 variant, the titratable acidity is lower by $0.6 \mathrm{~g} / \mathrm{l}, \mathrm{pH}-$ by 0.2 , the content of phenolic substances - by 90 $\mathrm{mg} / \mathrm{l}$, glycerin - by $0.6 \mathrm{~g} / \mathrm{l}$ than in the U/C variant. The content of phenolic substances and total dry extract in two variants corresponds to the category of rosé wines. The AZOS-1 bush training, in comparison with U/C training, contributed to a lower content of titratable acids, glycerin and phenolic substances in the base wine. However, organoleptic evaluation showed fuller taste and color in this sample. The tasting score of the samples was 7.8-7.9 points.

Thus, the studied forms of bush training: AZOS-1 and U/C ensure the production of standard grapes and base wines as meeting the requirements of GOST 32030.

When choosing one or another form of a grape bush training to give it the most advantageous shape in terms of: easy plant management, mechanical operations in the vineyard, increasing the grape producing capacity and product quality, it is necessary to estimate the time spent on pruning. The time spent on pruning of AZOS-1 bush was 1.44 times less than in the control, associated with the lack of the step of picking the cane off the trellis, due to the free placement of the increment in space (Figure 5).

When pruning 1 ha of vineyards using AZOS-1 training form, 7.0 person-days are required, which is $30 \%$ less than when pruning a vineyard according to $\mathrm{U} / \mathrm{C}$ bush training 10.0 person-days. Spiral cordon AZOS-1training of grape bushes eliminates dry and green tying. Pruning with this form of training is performed leaving 2-3 eyes long spurs, young shoots hang loose in the space of the vineyard row.

Thus, using of AZOS-1 training of grape bushes in commercial plantations has a number of advantages, both commercial and technological, as compared to cordon and other forms of training.

Cordon bushes of 'Cabernet-Sauvignon' R-5 grape variety in the experiment were cut on "renewal spur" and were compared with the "fruit section" pruning. The "renewal spur" pruning simplifies the technique of this agricultural practice with the same agrobiological parameters.

Time study of the pruning methods (Figure 6) showed the advantage of labor efficiency in the variant of experiment "renewal spur" in comparison with the control ("fruit section" pruning). 


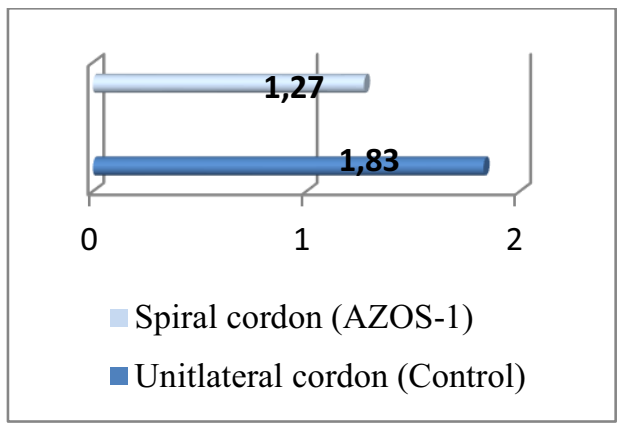

Fig. 5. Time study of the working hours, spent on grape bush pruning with different forms of training, 'Aleatiko' clone 802 and 'Muscat Blanc' clone VCR-3 grape varieties

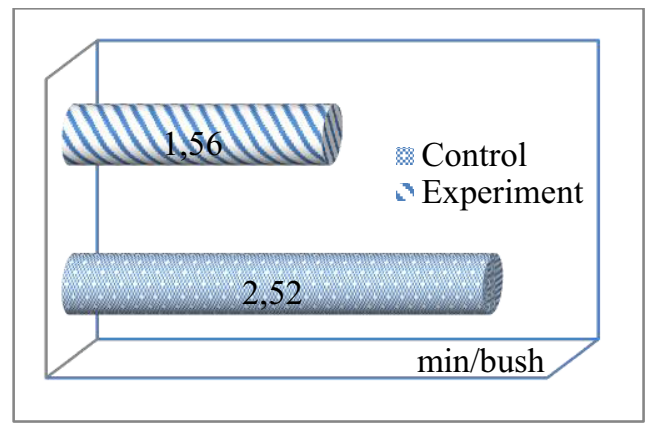

Fig. 6. Time study of the working hours, spent on different forms of grape bush pruning, training form is bilateral cordon, 'CabernetSauvignon' clone R-5 grape variety

Due to the improved technology (operation), in particular, with a "renewal spur" pruning, the labor efficiency has increased by 1.62 times. With the existing standard shifts for a grape bush pruning, taking into account the age of plantations and vigor of bushes, the labor efficiency is 229 bushes / shift. When using the "renewal spur" pruning on 3 eyes, in comparison with "fruit section" pruning on 6 eyes, labor efficiency increases - up to 352 bushes / shift and working time decreases by 2.8 person-days / ha.

The economic efficiency of cultivation the clones of European varieties is presented in Table 4. Cost efficiency of cultivation the 'Aleatiko' clone 802 variety using the AZOS-1 form is lower than the control (U/C) by $40.5 \%$. Using of AZOS-1 and U/C training for the variety 'Muscat Blanc' clone VCR-3 is characterized by the same values, which is higher than cost efficiency of cultivation the example variety 'Muscat Blanc' (control) by $39.4 \%$ and $36.8 \%$, respectively.

An increase in the cost efficiency of the 'Cabernet-Sauvignon' clone R-5 variety using $\mathrm{B} / \mathrm{C}$ form was registered in experimental variant $\mathrm{I}$, which is slightly higher than in experiment II by $8.1 \%$ and higher than in the example variety by $100.2 \%$.

As a result of scientific research, we have identified the experimental variants, which prevail over control and confirm the advantage of new method of grape bush training and management according to the reported values. The results of this study will make it possible to give recommendations to farms on the efficient management of the studied varieties in commercial vineyards.

In general, the development of new and improvement of existing agrotechnological methods of grape cultivation, including pruning and training of bushes, allows to increase the economic efficiency in viticulture.

Table 4. Economic efficiency of cultivation the clones of European varieties depending on the developed elements of cultivating technology.

\begin{tabular}{|c|c|c|c|c|c|c|c|c|}
\hline 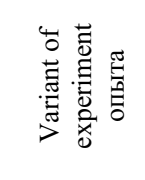 & & 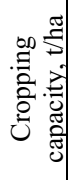 & 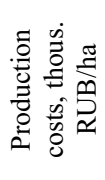 & 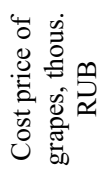 & 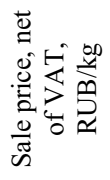 & 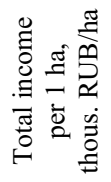 & 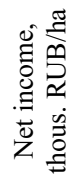 & 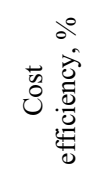 \\
\hline \multicolumn{9}{|c|}{ 'Aleatiko' clone 802} \\
\hline Experiment & $\begin{array}{c}\text { AZOS- } \\
1 \\
\end{array}$ & 7,2 & 221 & 30,7 & 60 & 432 & 211 & 95,5 \\
\hline $\begin{array}{c}\text { Example } \\
\text { variety }(\mathrm{C})\end{array}$ & $\mathrm{U} / \mathrm{C}$ & 8,7 & 221 & 25,4 & 60 & 522 & 301 & 136,0 \\
\hline
\end{tabular}




\begin{tabular}{|c|c|c|c|c|c|c|c|c|}
\hline \multicolumn{9}{|c|}{ 'Muscat Blanc' clone VCR-3 } \\
\hline Experiment I & $\mathrm{U} / \mathrm{C}$ & $\begin{array}{c}10, \\
3\end{array}$ & 209 & 20,3 & 55 & 566,5 & 357,5 & 171,0 \\
\hline Experiment II & $\begin{array}{c}\text { AZOS- } \\
1\end{array}$ & $\begin{array}{c}10, \\
2\end{array}$ & 209 & 20,5 & 55 & 561,0 & 352,0 & 168,4 \\
\hline $\begin{array}{c}\text { Example } \\
\text { variety }(\mathrm{C})\end{array}$ & $\mathrm{U} / \mathrm{C}$ & 8,8 & 209 & 23,7 & 55 & 484,0 & 275,0 & 131,6 \\
\hline \multicolumn{9}{|c|}{ 'Cabernet-Sauvignon' clone R-5 } \\
\hline Experiment I & \multirow{3}{*}{$\mathrm{B} / \mathrm{C}$} & $\begin{array}{c}10, \\
4\end{array}$ & 221,5 & 21,3 & 60 & 624 & 402,5 & 181,7 \\
\hline Experiment II & & $\begin{array}{c}10, \\
1\end{array}$ & 221,5 & 21,9 & 60 & 606 & 384,5 & 173,6 \\
\hline $\begin{array}{c}\text { Example } \\
\text { variety }(\mathrm{C})\end{array}$ & & 6,7 & 221,5 & 33,1 & 60 & 402 & 180,5 & 81,5 \\
\hline
\end{tabular}

\section{Conclusion}

The dependence of the economic efficiency of grape cultivation on the required elements of varietal agricultural technology have been established, agrotechnological and technological indicators of raw materials and base wines have been substantiated:

- the embryonic fertility of the studied clones of wine grape varieties is in direct correlation with the applied elements of varietal agricultural technology, characterized by a very high and high inflorescence initiation, exceeding $\mathrm{K}_{1}$ values of the example varieties;

- in SCC conditions high yields without loss of product quality can be obtained with the bush training forms: unilateral cordon, bilateral cordon and spiral cordon AZOS1. Selection of the training form of the studied clones of wine grape varieties will depend on the direction of use of raw materials;

- the studied forms of grape bushes ensure the production of high quality base wines with different organoleptic profiles;

- it was found that carrying out the agrotechnical activity on "topping" shoots on bushes with spiral cordon AZOS-1training of the 'Aleatiko' clone 802 variety, leaded to a decrease in parameters of the crown architecture;

- the developed elements of varietal agricultural technology, identified as optimal, improve quantitative and qualitative indicators of the studied clones of wine grape varieties;

- the efficiency of cultivation according to the developed elements of technology of clones of wine grape varieties is from 95.5 to $181.7 \%$.

- cultivation of varieties and clones using training form AZOS-1 and short pruning allows to reduce expenses and time (by 1.44 times) involved in the bush management compared to $\mathrm{U} / \mathrm{C}$ and $\mathrm{B} / \mathrm{C}$ training and "fruit section" pruning.

\section{References}

1. E.Sh. Shatskaya, Economics \& Law, 11-2(69), 16 (2016)

2. M. De Salvo, D. Begalli, R. Capitello, G. Signorello, Agricultural Systems, 141, 48 (2015)

3. Strategy of scientific and technological development of the Russian Federation: approved by executive order of the President of Russian Federation dd December 01, 2016. № 642 (Col. Of Legislation of the Russian Federation, 49, Art. 6887, 1674716976, http://legalacts.ru/ 
4. M.R. Beybulatov, N.A. Urdenko, N.A. Tikhomirova, R.A. Buival, Horticulture and Viticulture of the South Russia, 61(1), 54 (2020)

5. M.R. Beibulatov, N.A. Urdenko, N.A. Tikhomirova, R.A. Buival, Viticulture and Winemaking, 1, 15 (2018)

6. L.P. Troshin, Scientific Journal of KubSAU, 54(10), 18 (2012)

7. Atak, Arif \& Şen, Abdulbaki, Vitis vinifera, 49, 43 (2020)

8. R. D. Umarov, F. M. Magomedov, M. A. Arslanov, S. R. Khabibov, S.A. Salatova, AIC development problems of the region, 4,167 (2018)

9. M. K . Karaev, Z.B. Gadzhiev, Strategy of sustainable development and innovative technologies in horticulture and viticulture: Materials of the International scientificpractical conference dedicated to 80 anniversary of the HSL, Dr. Agric. Sci., Academician N.A. Aliev. Makhachkala: FGOU VPO "DGSKA", 129 (2010)

10. Sh. N. Ghuseynov, Scientific Works of North Caucasian Federal Scientific Center of Horticulture, Viticulture, Winemaking, 18, 24 (2018)

11. R. \& S., Rodríguez, M. \& T., Bernardita \& Peppi, M. Cecilia, Revista de la Facultad de Ciencias Agrarias, 45, 129 (2013)

12. G. \& P., Allegro, C. \& V., G. \& F., Ilaria, BIO Web of Conferences, 13, 04003 (2019)

13. O. P. Tkachenko, A. A. Shtirbu, Eureka: Life Sciences, 2, 34 (2017)

14. X. Yue, Y. Ju, Z. Tang, Y. Zhao, X. Jiao, Z. Zhang, Journal of Integrative Agriculture, 18(9), 2052 (2019)

15. A. M. Avidzba, Methodological recommendations on agrotechnical research in viticulture of Ukraine, 264 (Yalta: IV\&W Magarach, 2004)

16. GOST 31782-2012, Fresh grapes, machine and manual harvesting for industrial processing, Standard specifications (2012)

17. STO 01580301.001-2016, Juices, must, grape and fruit wines, low-alcohol drinks. Determination of the mass concentration of organic acids by the method of high performance liquid chromatography, 15 (Yalta, 2016)

18. GOST 32051-2013, Wine products. Organoleptic analysis methods. Moscow: Standardinform (2013)

19. STO 01580301.002-2016, Juices, must, grape and fruit wines, low-alcohol drinks. Determination of the mass concentration of organic acids by the method of high performance liquid chromatography, 14 (Yalta, 2016)

20. V.G. Gerzhikova, Methods of techno-chemical control in winemaking, 303 (Simferopol: Tavrida, 2009)

21. A.F. Chernyavskiy Increase in the economic efficiency of grapes, 63 (Simferopol: Krymizdat, 1986)

22. B.A. Dospekhov, Methodology of field experiment (with the basics of statistical processing of research results), 377 (Moscow: Kolos, 1985) 